\title{
O protagonismo Paiter Suruí no cenário educacional indígena: elementos para um diálogo possível de interculturalidade
}

\author{
Chicoepab Suruí \\ Universidade de Brasília. Terra Indígena Sete de Setembro - RO, Brasil. \\ Email: chsurui@paiter.org

\section{Almir Narayamoga Suruí} \\ Universidade Federal de Rondônia. TI Sete de Setembro - RO, Brasil. \\ Email:almir.surui@paiter.org

\section{Ivaneide Bandeira Cardozo}

Universidade Federal de Rondônia. Porto Velho-RO, Brasil.

E-mail: ivaneide@kaninde.org.br

\section{Emílio Sarde Neto}

Universidade Federal do Paraná. Curitiba - PR, Brasil.

E-mail: emiliosarde@hotmail.com

\section{Adnilson de Almeida Silva}

Universidade Federal de Rondônia. Porto Velho-RO, Brasil.

E-mail: adnilsonn@gmail.com

Resumo: O artigo propõe discutir os tipos de mudança da percepção que o povo indígena Paiter Suruí obteve a partir do processo de desenvolvimento econômico nos estados de Rondônia e Mato Grosso (ambos na Amazônia Legal brasileira) a partir de sua experiência vivida e do estabelecimento de relações com o mundo não indígena no uso do valor econômico de seu território, isto é, utilizandose de técnicas de diálogos entre dois conhecimentos, o próprio e o científico. O desenvolvimento da Amazônia contribuiu de forma significativa para a mudança na estabilidade econômica da etnia, seja com a influência sobre a comercialização da madeira, do extrativismo mineral e vegetal, do agronegócio e da introdução de novos valores culturais, sociais e políticos. Parte-se daqui que é quase impossível o retorno de certas práticas verificadas nos modos de vida indígenas antes do contato, no entanto, é necessário dialogar com esse encontro. Desse modo, pretende-se debater os desdobramentos que as atividades socioeconômicas trouxeram para esses povos, bem como de iniciativas e perspectivas relacionadas a projetos que se relacionam ao exercício das práticas e do etnoconhecimento como ferramentas indispensáveis ao processo de permanência cultural e de sobrevivência física e territorial - a educação para os Paiter Suruí é um dos pilares estratégicos que possibilitará a aquisição de 
novos conhecimentos, a ampliação de seus direitos e a conquista plena da cidadania.

Palavras chave: Amazônia, educação escolar indígena, modos de vida, protagonismos indígenas, perspectivas de desenvolvimento.

\section{The Paiter Suruí protagonism in the indigenous educational scenario: elements for a possible intercultural dialogue}

The article proposes to discuss the changes of perception that the indigenous people Paiter Suruí obtained from the process of economic development in the States of Rondônia and Mato Grosso (both in the Brazilian Legal Amazon) from their experience and the establishment of relations with the non-indigenous world in the use of the economic value of their territory; that is, using dialogue techniques between two knowledges: the scientific one and their own. The development of the Amazon has contributed significantly to the change in economic stability of ethnicity, with influence over the marketing of wood, vegetables, and mineral extraction of agribusiness and the introduction of new cultural, social and political values. Given this, the return of certain practices observed in the indigenous ways of life before the contact is almost impossible; however, due to this encounter, it is necessary to create a dialogue. In thus, we intend to discuss the unfolding that socio-economic activities have brought to these peoples, as well as initiatives and perspectives related to projects that refer to the exercise of practices and of ethnics knowledge, as essential tools for the process of cultural permanence and physical and territorial survival-education for the Paiter Suruí is one of the strategic pillars that will allow the acquisition of new knowledge, the expansion of their rights and the achievement of full citizenship.

Key words: Amazon, indigenous school education, ways of life, perspectives indigenous, development perspectives.

\section{El protagonismo Paiter Suruí en el escenario de la educación indígena: elementos para un diálogo intercultural posible}

Resumen: El artículo se propone discutir los tipos de cambio de la percepción que el pueblo indígena Paiter Suruí obtuvo a partir del proceso de desarrollo económico en los Estados de Rondonia y Mato Grosso (ambos en la Amazonia Legal brasileña) desde su experiencia y el establecimiento de relaciones con el mundo no-indígena en el uso del valor económico de su territorio, esto es, utilizando técnicas de diálogos entre dos tipos de conocimientos, el científico y el propio. El desarrollo de la Amazonia ha contribuido significativamente al cambio en la estabilidad económica de la etnicidad, con influencia sobre la comercialización de la madera, del extractivismo mineral y vegetal, de la agroindustria y de la introducción de nuevos valores culturales, sociales y políticos. De aquí se desprende que es casi imposible el retorno de ciertas prácticas observadas en las formas indígenas de vida antes del contacto, sin embargo, es necesario construir un diálogo en este proceso de encuentro. De esta manera, tenemos la intención de discutir los despliegues que las actividades socio-económicas han significado para estos pueblos, así como iniciativas y perspectivas relacionadas con proyectos que se vinculan con el ejercicio de las prácticas y del etno-conocimiento como herramientas fundamentales para el proceso de permanencia cultural y de supervivencia física y territorial - educación para los Paiter Suruí es uno de los pilares estratégicos que permitirán la adquisición de nuevos conocimientos, la amplia- 
ción de sus derechos y el logro de la plena ciudadanía.

Palabras clave: Amazonía, educación escolar indígena, formas de vida, perspectivas indígenas, perspectivas de desarrollo.

$* * *$

\section{Considerações iniciais}

O tratamento da questão indígena na Amazônia não difere em muito do que se verificam em relação ao Brasil e aos demais países da América. Ao longo da história deste continente os povos originários têm sido submetidos a uma série incontável de atrocidades, tais como: pressões das mais variadas intensidades entre elas os etnocídios, genocídios e perda de territórios, enfim trata-se da violação de seus direitos fundamentais.

O artigo procura demonstrar ainda que, de forma sucinta, a preocupação vivida na atualidade e as perspectivas e estratégias que os indígenas buscam para a manutenção dos valores culturais e a garantia de seus territórios e a incorporação de novos conhecimentos por meio da educação formal e formação de recursos humanos, para atuar dentro do território indígena.

Para além das questões teórico-conceituais, o trabalho empírico destaca os sentidos vivenciais e discursos dos Paiter Suruí que habitam a Terra Indígena Sete de Setembro (TISS - autodeterminada Paiterey Garah TIPG), localizada nos estados de Rondônia e Mato Grosso, ambos na Amazônia brasileira. Neste sentido, Almeida Silva considera que:

[...] a territorialidade e a espacialidade configuram-se como expressões que estão imbricadas da ideia de pertencimento cultural, sendo parte inseparável dessa interpretação, porque carrega a compreensão de relação espacial. Pelo vínculo de pertencimento, essa conexão com o espaço é traduzida pelos sentimentos e a valoração que se opera sobre esse, de modo que é possível pensar o espaço de ação como um dos elementos que contribuem diretamente na construção cultural, identidade, pertencimento e enraizamento de um determinado coletivo. No caso dos indígenas, esse constructo está diretamente conectado às experiências de ancestralidade e de cosmogonialidade, nas quais depositam a confiança nos espíritos e na relação intrínseca com o meio, pois os divíduos se corporificam, presentificam, representam e são formas que possibilitam a operacionalização desse constructo. (Almeida Silva, 2010: 83-84).

Com isso, o estudo não se trata de uma comparação étnica, mas procura refletir sobre como esses povos constroem territorialmente sua relação com o "desenvolvimento" e a sociedade abrangente e/ou envolvente nacional, isto porque ambos possuem diferentes escalas temporais e geográficas de aproximação com essa sociedade. 
Isso significa que as relações sociais estabelecidas são detentoras de condições distintas de realidades e de significados, os quais implicam em graus específicos de interação com os mais diversos atores sociais. Logo, não se discute as questões indígenas se não considerarmos a cultura como fenômeno revelador da identidade, isto porque a cultura "produz o sentido de afirmação, de pertencimento no mundo e de representar-se perante o Outro, e possui como característica o processo de incorporação, como refazer-se dialeticamente, mas não como um processo de negação do seu Eu e do seu Outro Eu” (Almeida Silva, 2010: 93). A partir dessas considerações, apresentamos algumas peculiaridades gerais inerentes aos Paiter Suruí.

\section{Os Paiter Suruí}

No século XIX, com a construção da Estrada de Ferro MadeiraMamoré inicia-se povoamento da região em que hoje se encontra o estado de Rondônia, tendo como base a política do Governo Federal de atrair trabalhadores para a essa zona. Um século depois, nos anos de 1960 e 1970, as políticas de colonização induzidas pelo Governo Federal, com a construção das rodovias de integração nacional que promoveram uma reconfiguração territorial e potencializaram as tensões e impactaram as populações indígenas. O sistema produtivo dos imigrantes que se instalaram na Amazônia rondoniense implicou em forte ação de desmatamento e degradação ambiental, principalmente nas proximidades das terras indígenas.

No caso rondoniense, as primeiras terras indígenas (TIs) foram institucionalizadas há pouco mais de quatro décadas, sendo que ainda existem povos indígenas sem territórios demarcados pelo Estado brasileiro, o que os coloca em risco maior de sobrevivência em decorrência de pressões oriundas do avanço da fronteira econômica. A noção de TIS, de acordo com Gallois (2004: 38-39):

(...) diz respeito ao processo político- jurídico conduzido sob a égide do Estado, enquanto a de território remete a construção e a vivencia, culturalmente variável da relação entre uma sociedade especifica e sua base territorial. (...) Na transformação de um território em terra, passa-se das relações de apropriação (que prescindem de dimensão material) à nova concepção de posse ou propriedade.

Neste sentido é pertinente observar que a problemática ultrapassa os quesitos de territorialidade e incidem diretamente sobre a própria sobrevivência dos povos indígenas, conforme contextualiza Almeida Silva:

Mesmo as TIs demarcadas e homologadas recebem pressões de toda ordem, tais como: invasão de posseiros, madeireiros, 
garimpeiros, fazendeiros, sitiantes, caçadores, pescadores; impactos diretos e indiretos de usinas de pequeno, médio e grande porte produtoras de energia, estradas; poluição e contaminação dos cursos d’água; cidades e vilas construídas próximas às TIs, entre outros, de modo que inúmeros problemas ecoam internamente - drogas, álcool, delitos e outras questões que promovem substanciais transformações no modo de vida. (Almeida Silva, 2012: 11).

Conhecidos como os Suruí de Rondônia, se autodenominam Paiter, que significa “gente de verdade”, nós mesmos (Mindlin, 1985: 13). Juntamente com outros indígenas da região, como os Cinta-Larga, Zoró e Gavião, falam a língua do tronco Tupi, da família Mondé. Desta forma, ao longo do texto será utilizado o termo Paiter Suruí para se referir a este povo originário e, em especial, às pessoas que foram entrevistadas com a finalidade de fornecer dados e informações para o presente estudo (Suruí, 2013).

Sua organização na atualidade é baseada em quatro diferentes clãs, os quais constituem o sistema de governança, a organização política, a rede de parentesco e matrimônio deste povo - marcada pela patrilinearidade. Os clãs são Gameb (marimbondos pretos), Gabgir (marimbondos amarelos), Makor (taboca, uma espécie de bambu amazônico) e Kaban (mirindiba, uma fruta regional).

O contato oficial foi estabelecido pela Fundação Nacional do Índio - FUNAI há somente 44 anos, ou seja, em 07 de setembro de 1969. É oportuno constatar que anteriormente ao ano citado, os Paiter Suruí já sofriam com ações de seringalistas, seringueiros e garimpeiros que adentravam em seu território ancestral, porém o contato com a FUNAI uma espécie de "rendição" - potencializaram as pressões marcadas com assentamento de colonos oriundos de outras regiões brasileiras, com conflitos e disputas de terras; pela construção de estradas e cidades próximas ao entorno; pelo surgimento de doenças, até então desconhecidas, que dizimaram praticamente toda a etnia; pela apropriação ilegal de produtos madeiráveis, entre outros, e com isso ocorrendo à usurpação das terras ancestrais.

Pelos relatos dos mais idosos do povo Paiter Suruí a população ultrapassava 5.000 pessoas e caiu para aproximadamente 250 nos primeiros anos do contato, devido a doenças como sarampo, gripe e pneumonia, entre outras. Atualmente, ocorre um crescimento populacional que aproxima de 1.450 pessoas distribuídas em 25 aldeias (Figura 01), sendo evidenciado que quase todo o entorno da TISS/TIPG foi desmatado por fazendeiros e pequenos colonos, que vieram para o Estado de Rondônia no final da década de 1960 e início da década de 1970. 


\section{Figura 01. Localização da Terra Indígena Sete de Setembro e das aldeias}

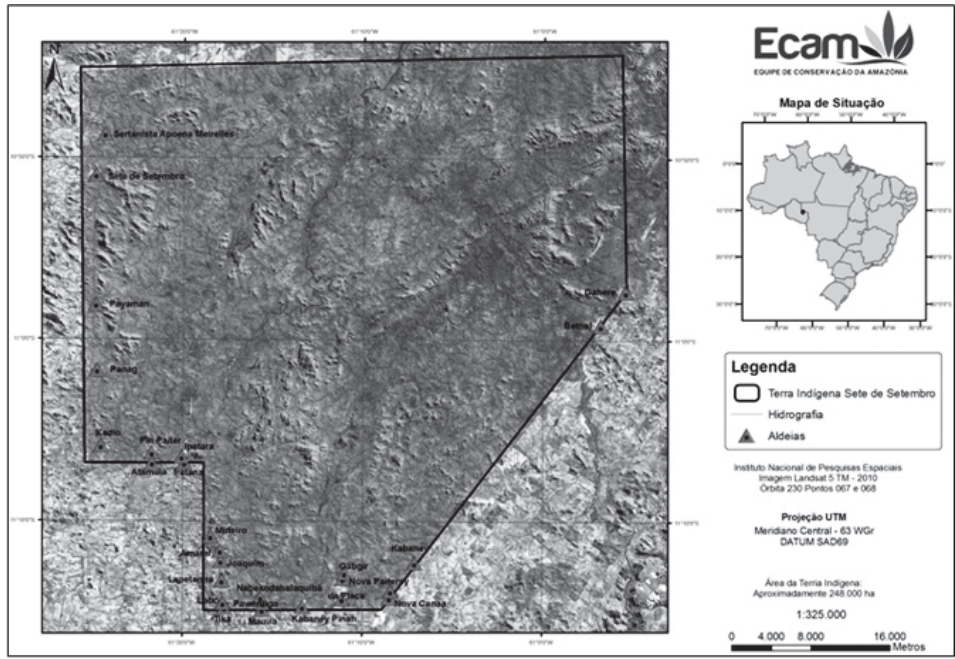

Fonte: ECAM apud Suruí, Chicoepab (2013).

Aqui cabe mencionar que o contato oficial com os Paiter Suruí está relacionado tanto a fatos históricos quanto geográficos e geopolíticos, em virtude de várias situações ocorridas no país, das quais destacamos alguns delas: 1) a implantação do regime militar no Brasil (1964-1984); 2) a aplicação da doutrina de segurança nacional; 3) a ocupação do "vazio demográfico" amazônico; 4) a efervescência de reivindicações sociais, especialmente no sul e sudeste, como reforma agrária; 5) a modernização da agricultura provocando o êxodo rural com consequente marginalização nas cidades. Desse modo, se transfere os problemas de outras regiões para a Amazônia, o que implicou diretamente no choque intercultural, isto é, entre aqueles que habitavam há séculos e tempos imemoriais e os migrantes.

No caso dos Paiter Suruí seu território foi reduzido em aproximadamente 4/5, o que corresponde na atualidade em cerca de 248.000 hectares, cuja área incide sobre os municípios de Rondolândia (Mato Grosso), Ministro Andreazza e Cacoal (Rondônia). A TISS/TIPG foi homologada oficialmente em dezembro de 1983, pelo Decreto nº 88.867 quando seu território era ainda ocupado por várias propriedades privadas, posseiros ou grileiros.

É oportuno destacar que a perda de parte do território, a modificação do espaço devido à ação do Estado e dos invasores, levou os Paiter Suruí a desterritorialização e a desenvolver estratégia de resistência, de modo que passam a ocupar os limites do território, realizam diagnósticos, etnozoneamento, planos de gestão territorial e ambiental, formalizam 
parcerias, buscam formação educacional formal, planos de negócios, procuram fortalecer a cultura como permanência identitária, desenvolvem projetos socioambientais, criam associações de promoção e auxílio na defesa dos seus direitos, criam fundo de gestão financeira e retomam o sistema de governança Paiter Suruí.

A apropriação e a modificação do espaço geográfico pode ser entendida como processos de territorialização ou dependendo das circunstâncias passa a ser concebida como desterritorialização ou des(re)territorialização, o que no caso das populações indígenas se insere na categoria de desterritorialização, isto devido perder parte de seu espaço ou esse ser descaracterizado de sua forma original, através da ação do Estado ou pelos grupos sociais detentores do Capital (Almeida Silva \& Leandro, 2010: 48).

Dessa forma, dentro das estratégias encontradas para salvaguardar o território, as aldeias que antes ficavam no interior da TISS/TIPG, foram deslocadas para ocupar o espaço demarcado pelo Estado brasileiro, com isso ficam situadas nos limites com propriedades rurais privadas, sendo uma forma tanto para a proteção do território, quanto para a preservação dos recursos naturais e culturais.

A situação dos Paiter Suruí possui muita semelhança com os MbyaGuarani na Argentina, que tiveram seu território reduzindo a cinco por cento da superfície do original, por uma decisão do Estado Argentino (Badie, 2008).

Durante todo el siglo XIX y parte del XX, la selva fue considerada en el discurso oficial argentino como un ámbito inhabitable y amenazador, radicalmente opuesto a la civilización. Simultáneamente, era visto como un reservorio ilimitado de posibilidades para la modernización, por lo que debía ser colonizado y explotado rápidamente. En tiempos relativamente recientes, este paisaje ha resurgido como referente de la integración transnacional, revirtiendo la tendencia que había predominado hasta entonces. (Wilde, 2007: 101)

Esta nova configuração territorial, por sua vez, exige novas formas de uso, de fortalecimento da cultura e da autonomia do povo, de modo que proporciona um novo planejamento e implementação na gestão do território. Neste caso, se insere novos “marcadores territoriais” (Almeida Silva, 2010), os quais se realizam tanto na definição do uso econômico sustentável, como na valorização dos espaços espirituais e culturais, para tanto, os Paiter Suruí desenvolvem o mapeamento cultural e o etnozoneamento, como alguns instrumentos que propiciam os arranjos territoriais e definem políticas de gestão.

A modificação do espaço, imposta pelo desenvolvimento pensado pelo Estado para a região, trouxeram novas estratégias de resistência para manter o território agora reduzido. As reflexões sobre como os Paiter Suruí 
resistiram e como representam esta resistência, nos remetem ao que afirma Lefebvre:

Entre as representações, umas são engendradas pelas relações e pelo modo de produção e se põem a serviço de ambos, elaborandose em ideologia e cientificidade. Outras vêm de mais longe, do mais profundo, de sociedades anteriores, de mitologias, de religiões. Com o passar do tempo foram sendo modificadas, desprendendo-se dos arquétipos simbólicos. Passaram então a servir para dissimular, simulando outra coisa. Estão em todas as mentes. (Lefebvre, 1980: 69 apud Rua, 2005: 130).

Nesse sentido, Chicoepab Suruí compreende que “nossa vida cotidiana praticamente mudou, hoje nós queremos ter dinheiro, e para esse querer, alguns Paiter Suruí vem tirando madeira do território de uma forma ilegal, sem pensar que isso pode prejudicar o nosso território e nossa cultura” (depoimento em outubro de 2013). Em sua concepção, essa mudança oferece um grande risco da perda cultural e territorial para os Paiter Suruí.

\section{Acerca de algumas problemáticas no Território}

No contexto do desenvolvimento econômico acelerado brutalmente na Amazônia, o entorno da TISS/TIPG é um foco constante de pressão externa para o interior do território, haja vista a vegetação ter sido suprimida no seu entorno e os proprietários rurais (pequenos, médios e grandes) muitas vezes permitirem que madeireiros adentrem a TI para roubar madeira ou ainda que garimpeiros e outros atores sociais invadam o território e praticam a depredação ambiental.

Soma-se a isso, o fato que alguns Paiter Suruí se ludibriaram ou coagidos a se envolver com madeireiros e também passaram a praticar a extração ilegal de madeira, enquanto outros arrendaram espaço de manejo da bovinocultura para os fazendeiros (Euler et al, 2008). É necessário acrescentar que essa ação dos indígenas está relacionada à omissão do Estado no seu papel de fiscalizador e indutor de políticas públicas que possibilitem a cidadania das populações indígenas que ficam à mercê de interesses obscuros de parte da sociedade nacional.

Diante desta realidade os Paiter Suruí buscaram alternativas para o uso sustentável do seu território, de modo a se adequar na economia da sustentabilidade com vista à preservação como um povo dotado de cultura distinta do restante da sociedade nacional.

Destarte procuraram auxílio para a elaboração de um Plano de Gestão do Território com horizonte de médio e longo prazo, sendo que durante sua construção, vários Paiter Suruí explicitaram que era quase impossível viver sem interferência em sua cultura e que necessitavam da cultura externa para 
sua sobrevivência como um povo. Entrementes, o povo Paiter Suruí vem adquirindo novos valores, sentidos de compreensão dos códigos da sociedade envolvente nacional e internacional, ou seja, se adaptando para sobrevivência dentro do sistema capitalista que envolve tanto o povo quanto o território.

E sempre com possibilidade do estabelecimento do diálogo entre dois conhecimentos: o etnoconhecimento e o conhecimento científico, que foi concebido o Plano de 50 anos Paiter Suruí como perspectiva viável à geração de renda na TISS/TIPG, bem como na salvaguarda deste território, entre outras possibilidades que assegure a pertinência cultural, social, política e ambiental. O Plano tem como escopo a formação de uma consciência de economia ambientalmente sustentável, e que possa contribuir globalmente com ações que possam minimizar o impacto no e do clima.

Elaborado a partir de 2000 pela Associação Metareilá do Povo Indígena Suruí em parceria com a Kanindé Associação de Defesa Etnoambiental, o Plano de Gestão Etnoambiental da TISS/TIPG, ou mais conhecido como Plano de 50 anos Paiter Suruí tem provocado uma série de mudanças de estabilidade econômica, para que sejam ambientalmente sustentáveis (Kanindé \& Metareilá, 2009: 25), ou seja, “a gestão do território Paiter Suruí é realizada de forma participativa e os projetos sustentáveis são exemplo a ser seguido" (Cardozo em comunicação pessoal em 21/julho/ 2012). Por essa conjectura entende-se que é possível elaborar plano de desenvolvimento econômico conscientemente e sustentavelmente em um determinado território indígena (Cardozo, 2010: 8).

Assim, ao estudar o modo de vida deste povo e as relações que estabelecem com a sociedade envolvente é indispensável considerar como ocorre o processo de interação e os mecanismos de estabilidade e mudança que enfrentam no cenário Amazônico inserido na lógica do modelo de desenvolvimento econômico atual.

No caso dos Paiter Suruí na concepção de Almir Narayamoga Suruí, um dos caminhos possíveis para o território consiste no reflorestamento de áreas que foram antropizadas - aproximadamente 7\% da área demarcada sendo uma das formas de desenvolvimento econômico sustentável (comunicação pessoal, junho/2010). No sentido genérico de procedimentos abre-se a perspectiva da utilização sustentável dos recursos naturais e a participação nas políticas públicas do meio ambiente visando alternativa econômica do território, através de projetos sustentáveis e para isso é indispensável à formação educacional aliando o etnoconhecimento e o conhecimento científico.

No bojo do Plano encontra-se o Projeto Carbono Florestal Suruí que a exemplo de várias outras atividades previstas e em execução, destaca-se a educação e a cultura, como um fator que poderá agregar novos valores e conhecimentos, de forma que o povo obtenha a autonomia econômica e também, sejam multiplicadores de experiências junto à sociedade envolven- 
te nacional. O aludido Projeto considera as seguintes questões como pertinentes ao processo:

1 - Áreas de significativo valor para a conservação (endemismo, espécies ameaçadas e risco de extinção, refúgios, áreas sagradas); 2 - Áreas de paisagem natural não alterada e detentora de espécies importantes para a conservação tanto do ponto de vista ambiental como cultural; 3 - Áreas de ecossistemas com espécies raras, ameaçadas ou em risco de extinção; 4 - Áreas onde se possam garantir os serviços ambientais (proteção de nascentes, lagos, etc.); 5 Áreas de uso da comunidade (roças, aldeias, saúde, educação, etc.); e 6 - Áreas culturais, ecológicas e podem ser desenvolvido ações voltadas ao desenvolvimento econômico (Leandro, 2011: 97).

Assim observa-se que o modo Paiter Suruí de viver e olhar o mundo ocorre com uma percepção interligada, logo o seu território é gerenciado pelo viés do etnozoneamento, com espaços específicos, conforme destacado na citação acima por Leandro (2011).

\section{Uma prévia abordagem sobre a escola e a educação escolar indígena na Amazônia}

A escola indígena na Amazônia brasileira reflete as modificações adquiridas no contato com a sociedade nacional, alternando-se em uma simbiose do moderno globalizado, com a visão romântica do indígena natural. A educação escolar indígena procura enfatizar a importância da comunidade na construção de uma educação diferenciada que respeite as especificidades de cada povo ou etnia. Na prática busca a aplicabilidade dos etnoconhecimentos no espaço escolar e com a absorção dos conhecimentos formais e sistematizados, ou seja, os acadêmico-científicos.

Muitas são as demandas que implicam na construção de estratégias de atendimento mais eficientes e concretos, que surgem como desafios a serem superados. Em consequência dessas demandas, é de fundamental importância o aparelhamento das escolas e das equipes que atendem os indígenas dentro dessa perspectiva globalizante.

A educação escolar indígena prossegue em passos lentos apesar das grandes conquistas realizadas. Deste modo podemos enumerar alguns problemas crônicos existentes: a) suas atividades seguem em acordo com a realidade estrutural das Secretarias de Educação dos estados e municípios; b) Muitos são os contratempos para a aplicabilidade das políticas públicas; c) funcionários com cargos de chefia e responsabilidade pela educação que possuem interesses políticos diretamente ligados aos latifúndios, dificultando o atendimento e o processo de ensino e aprendizagem das escolas indígenas; d) material didático incompatível com a realidade vivencial dos discentes indígenas; e) recusa dos órgãos públicos do setor em contratar e 
disponibilizar equipe de técnicos e professores indígenas e não indígenas para as escolas; f) escolas construídas em padrões arquitetônicos urbanos que produzem resistências e topofobias no ambiente educacional. Soma-se a essas questões o fato que a maioria das escolas indígenas se encontra em regiões de difícil acesso, logo a falta de transportes fluviais e terrestres prejudica a chegada de materiais (merenda escolar, livros etc.) necessários ao desenvolvimento das práticas pedagógicas.

Apesar de muitos professores indígenas que atuam em sala de aula ser indicados pela própria etnia, a luta pela autodeterminação das escolas parece uma conquista ainda muito distante do que almejam em termos de atingir os mesmos níveis adotados principalmente pelo Sistema de Avaliação da Educação Básica (Saeb) e pelo Exame Nacional do Ensino Médio (Enem), este último em menor escala, devido esta modalidade ser mais recente.

Os poucos professores não indígenas disponibilizados para o atendimento às escolas não possuem conhecimentos específicos na área de antropologia e história das comunidades atendidas, de modo que em muitos casos acabam por reproduzir preconceitos e lógicas que se distanciam da realidade indígena. A falta de estrutura nas aldeias como alojamentos para os professores e saneamento básico dificulta a permanência desses profissionais nas TIs, além do que possuem um perfil urbano e possuem necessidades que não podem ser atendidas nas aldeias.

Em muitas aldeias existe a necessidade do ensino médio regular e técnico para atender as demandas profissionalizantes dos jovens e evitar que os discentes estudem na cidade e enfrentem as dificuldades de viver longe dos seus valores culturais e expostos aos riscos da vida urbana. Assim, ao se pensar o ensino médio como continuidade do ensino fundamental é indispensável que no contexto da lógica indígena se preocupe com a manutenção do território como espaço para as crianças e a juventude, pois é nele que está a permanência e a valorização de sua identidade e de seu pertencimento como povo.

Discutir o uso do território, a produção e a sustentabilidade criam possibilidades dos produtos das aldeias serem uma alternativa para o sustento das famílias, sendo que nas escolas é possível trabalhar por meio de temas transversais a produção e a geração de renda com o objetivo de desenvolver um projeto interdisciplinar e intercultural para os discentes saberem distinguir quais são os produtos tradicionais e suas funcionalidades cosmogônicas, e quais os produtos introduzidos após o contato com a sociedade envolvente nacional.

As escolas indígenas possuem a liberdade na construção dos seus currículos educacionais; além das disciplinas que já estão na organização curricular, outras podem ser criadas pelos professores indígenas como literatura indígena na própria língua materna e com isso reforçar o papel de sua identidade étnica. $\mathrm{O}$ atendimento específico, diferenciado e de qualidade é direito dos povos indígenas e dever do Estado, mas ainda em muitas Secre- 
tarias de Educação são impostos currículos autoritários, assimilacionistas e descolados da realidade em que vivem estes povos com suas multiplicidades de saberes e culturas imemorialmente construídas.

\section{A governança Paiter Suruí e a importância da educação}

Em virtude do processo de esfacelamento do território e preocupados com a permanência cultural os Paiter Suruí, ao final dos anos 1990, internamente chegaram à conclusão que era imprescindível instituir novas estratégias de diálogo com a realidade sociopolítica existente e com a política desenvolvimentista do país, de modo que garantissem a sobrevivência física e espiritual e salvaguardassem o território demarcado. Para tanto, com o apoio do Ministério do Meio Ambiente e da Associação Kanindé, realizaram em 2000 o Diagnóstico Agroambiental Participativo e o Plano de Gestão Etnoambiental da TISS/TIPG.

O Plano de Gestão tem como objetivo implementar o Programa Paiterey para a gestão ambiental e territorial, estabelecendo procedimentos e diretrizes para o encaminhamento das demandas socioculturais, de forma a permitir condições para o uso responsável dos recursos naturais, gerando os benefícios necessários, a valorização da cultura, a geração de rendas e a conservação do meio ambiente (Kanindé \& Metareilá, 2009), baseado em subprogramas temáticos.

É necessário destacar que os Paiter Suruí compreendem que as ações dos instrumentais (Diagnóstico, Plano de Gestão, Etnozoneamento, entre outros) devem ser integradas, portanto, ao falarem de saúde estão abordando também a educação, a segurança alimentar, a proteção territorial, a geração de renda, o meio ambiente, a moradia e a cultura. Em tal sentido, concebem que o modo de viver peculiar está intimamente ligado à natureza, especialmente a floresta que é de grande importância para sustentabilidade da cultura, tradição, rituais, alimentos e a própria existência do povo, como pode ser constatado na afirmativa do líder João Lawad Suruí:

Eu posso dizer que (nosso) o ancião não veja apenas a si próprio! Ele vê o futuro (o que vem), dos filhos, dos netos e dos bisnetos! E pensando neles que preservaria a floresta. E dar sustentabilidade a cultura, a floresta, não simplesmente a floresta, mas sim, do que era beneficiado dela, para que futuro geração venha a ser beneficiada também. Tenho certeza que quanto não cuidar bem, acaba a floresta. Veja aqui área de reflorestamento, estão de novo existindo plantas nativas, se não houvesse essa ideia, não existia essa espécie aqui. Quem vai ser beneficiado desse reflorestamento, são as crianças Gabgir, como também as crianças de outras aldeias. Veja aqui pé de castanha, ela vai existir muitos anos aqui. E vai ser para muitas coisas, a castanha iremos utilizar para alimentação e para vender, como também o pé serve como a madeira. E do pé da castanha também 
tiramos a corda, para fazer artesanato Paiter (para fazer balaio, cesto para carregar caça) (comunicação pessoal em 09 de dezembro/2012).

Desse modo, ao se analisar o discurso de João Lawad Suruí é perceptível que ele trata de vários elementos que está interconectado à educação e à cultura de seu povo, como: a segurança alimentar, a sustentabilidade, a produção florestal, a preservação e conservação ambiental, sendo que todas estão inseridas num contexto pertinente à própria sobrevivência. Aliás, esse sentimento encontra-se expresso, como governança, na execução do Programa Paiterey voltada à gestão ambiental, em que se estabelecem os procedimentos e diretrizes para o encaminhamento das demandas socioculturais, de maneira que busca permitir condições para o uso responsável dos recursos naturais gerando os benefícios necessários, a valorização da cultura e a conservação do meio ambiente.

Entre os fundamentos do Programa Paiterey dos dez objetivos específicos que estão interligados entre si, cinco deles consideramos como bem explícitos ao tratar sobre as perspectivas do papel educacional, sendo: a) Desenvolver projetos alternativos de produção de alimentos, farmácia viva, habitação sustentável e geração de excedentes comercializáveis; b) Promover a cultura Paiter Suruí, com a criação do Centro de Formação e Pesquisa Indígena para divulgação da cultura na sociedade regional, nacional e internacional; c) Implantar a Escola Agroambiental Paiterey como instrumento para repasse de conhecimentos ambientais sobre uso dos recursos naturais; d) Implantar a Universidade Indígena Paiterey; e) Implantar o Centro de Cultura e Tecnologia Paiter, onde serão apoiados indígenas para realizarem junto com pesquisadores não indígenas pesquisas culturais e científicas, via convênios e parcerias com instituições e institutos de pesquisa, faculdades, ONGs e empresas.

Na concepção educacional os Paiter Suruí apontam a necessidade de unir seu etnoconhecimento (informal) com o conhecimento sistematizado e acadêmico-científico (formal), para tanto, tem buscado parcerias nacionais e internacionais com universidades, instituições de ensino fundamental e médio, entidades não governamentais.

Compreendem que é indispensável à adoção de métodos formais de aprendizado, nos quais se incluem a continuidade e a ampliação da formação de professores indígenas, como forma de passar essa atribuição à própria comunidade. Em tal sentido projetam a criação de uma escola formal que possibilite a continuidade a uma formação diferenciada, ou seja, incorporando a lógica temporal e o conhecimento do povo com o saber científico.

Neste contexto, aproximadamente dez estudantes encontram-se cursando nível superior, um jovem (Chicoepab Suruí) defendeu o Mestrado Profissional em Desenvolvimento Sustentável na Universidade de Brasília, acrescentando-se ainda que a Universidade Federal de Rondônia, por indicação do Programa de Pós-Graduação Mestrado em Geografia, outorgou 
o título de Doutor Honoris Causa ao líder maior dos Paiter Suruí, Almir Narayamoga Suruí - em reconhecimento a seus relevantes serviços prestados à humanidade - inclusive este líder integra o corpo docente do referido Programa de Mestrado.

O que se observa e é intencionado como politica educacional e anseio dos Paiter Suruí - considerando o contato realizado há menos de cinquenta anos - é que se desenvolvam como parte de sua estratégia, os seguintes objetivos:

a) produzir conhecimentos que permitam conciliar o saber ancestral (etnoconhecimento) com a realidade formal acadêmico-científica em que os indígenas sejam protagonistas desse processo;

b) desenvolver iniciativas e projetos a partir da realidade existente incorporando a forma acadêmica, mas com base em uma educação alternativa e inclusiva dentro do contexto comunitário desde o ensino fundamental ao universitário, inclusive aqueles de altos estudos, como mestrado e doutorado nas mais diversas áreas do conhecimento;

c) desenvolver práticas e experiências que considerem o indígena como sujeito de sua história e investigador de práticas de investigação - com pesquisas de diferentes contextos, sobretudo sob o ponto de vista intercultural;

d) oferecer elementos que possibilitem o avanço metodológico e conceitual acerca de formulação de novas perspectivas quanto à produção do conhecimento a partir das vivências e experiências focalizadas no etnoconhecimento ou conhecimento êmico, ou seja, dos próprios discursos e conceitos que podem explicar outro olhar sobre o mundo em suas mulpiplas relações.

No constructo do processo educacional, os Paiter Suruí consideram que o "modelo" que deve integrar o conhecimento, pelo menos nos primeiros anos de formação dos discentes não pode ser outro se não aquele que prevê a aplicação de métodos autônomos de ensino-aprendizagem, compreendidos aqui como a predominância dos aspectos informais - isto porque está relacionado à compreensão da endocultura, pois possuem como princípio maior que os indígenas devem ser formados e diplomados para atender prioritariamente a própria etnia como processo que permita a sustentação do etnodesenvolvimento do povo.

No conjunto do contexto educacional possuem a compreensão que além do ensino formal não podem abdicar da preparação para o mercado de trabalho - ainda que no âmbito interno - para tanto, a capacitação continuada, inclusive daqueles que não frequentam a sala de aula deve se estender às unidades familiares, visto que essas necessitam compreender processos que possam garantir não apenas a produção, mas a subsistência das famílias, 
entendidas aqui como segurança alimentar, segurança de saúde e territorial.

O Centro de Formação Paiter apresenta-se como realidade concreta, visto que os Paiter Suruí já disponibilizam de espaços adequados e constantemente utilizados em capacitação e formação de recursos humanos, sendo que desde 2007 estabeleceu parceria com o Google Earth que ofereceu curso de ferramentas tecnológicas no uso da internet.

Com a parceria com o Google foi perceptível uma série de avanços que possibilita a visibilidade dos Paiter Suruí, isto porque os indígenas receberam treinamentos específicos que permitiu a utilização de tecnologia, conforme afirma Almir Narayamoga Suruí: "passaram a valorizar a história dos anciãos e a guardar, em vídeos e fotos on-line, as tradições da aldeia. Ainda se valeram de smartphones e GPS para identificar os desmatamentos ilegais".

A importância dada ao novo não significa o abandono da cultura, antes reforça seu papel frente aos desafios que são colocados na realidade do povo, esta compreensão é dada pelo líder Almir' ao inferir que: "Desde quando os Suruí e outros povos indígenas receberam ferramentas de treinamento do Google, nossa terra recebeu maior visibilidade. Todas as informações lançam uma luz sobre a inovação de nossa terra... e colocam nas mãos de nosso povo a responsabilidade por seu próprio futuro".

Esse novo conhecimento com a utilização da tecnologia permitiu que os Paiter Suruí criassem um mapa cultural online ${ }^{2}$, que apresenta interatividade, visto que reúne histórias e narrativas míticas do povo, bem como um mapa geográfico do território Paiterey Garah criado com aparelhos de GPS fornecidos pela parceria. Ainda como parceria a empresa disponibilizou funcionários para ensinaram o povo a utilizar celulares para registrar ilegalidades cometidas, principalmente por madeireiros no interior da Terra Indígena. Desse modo, os indígenas registram fotos e produzem vídeos com georreferenciamento que posteriormente são postados no Google Earth e com isso permitem que façam monitoramento do território e ofereçam denúncias aos órgãos competentes.

Desta forma, a educação para os Paiter Suruí está associada e interligada a outras questões que normatizam o modo de vida, como afirma Chicoepab Suruí “O meu povo vem buscando o planejamento de atividades que contribuam com o seu desenvolvimento econômico e que sejam ambientalmente sustentáveis, garantindo assim a proteção e conservação dos recursos naturais da TISS/TIPG e contribuindo na luta a favor das mudanças climáticas”.

Ainda no Centro de Formação Paiter Suruí, com apoio do Ministério da Cultura e da Superintendência dos Esportes, da Cultura e do Lazer de Rondônia (SECEL), a Associação Metareilá do Povo Indígena Suruí desenvolve o Projeto Maloca Digital que tem como objetivo a implantação dos chamados "Pontos de Cultura”, onde os indígenas utilizam a tecnologia 
digital para divulgar sua cultura, além de incluí-los digitalmente. As Associações Kanindé e Metareilá realizaram nestes espaços uma pesquisa sobre o que os indígenas compreendiam e se pretendiam desenvolver o turismo na TISS/TIPG. A pesquisa subsidiou as oficinas de capacitação em ecoturismo e teve como resultado dois trabalhos de conclusão em Turismo, sendo um deles de autoria de Gasodá Suruí (Cardozo, 2013: 44-46), e ainda de três dissertações de Mestrado em Geografia da Universidade Federal de Rondônia.

Em relação à Escola Agroambiental Paiterey ainda está em fase de planejamento e no conjunto programático do Plano de Gestão estará voltada à capacitação e vivência ambiental que incorporará a saúde integral, sistemas agroflorestais, manejo florestal, alternativas de produção e verticalização da alternativa econômica, ecoturismo e colocação de produtos no mercado, parece evidente que se trata de uma proposição concreta que permitirá aos Paiter Suruí não somente a salvaguarda do território e a permanência cultural, mas ser um referencial para outros povos indígenas e populações da América Latina e do mundo (caso esses entendam como coerente a seus projetos de vida).

Para tanto, o espaço que será construído para a escola ficou definido às margens do rio Branco, local onde foi realizado o primeiro contato e dela participarão unidades familiares de produção com representantes de todas as aldeias. No projeto prevê que a administração pedagógica e financeira será realizada de forma autônoma pelos Paiter Suruí, por intermédio da Associação e estará aberta à parceria de outras instituições.

Quanto à Universidade Paiterey foram iniciadas as primeiras discussões com as lideranças do povo e instituições de ensino superior da região, pretende-se que a concepção do projeto seja semelhante ao verificado na experiência de outras universidades indígenas existentes na América Latina. É importante destacar que o Ministério da Educação brasileiro constituiu um grupo de trabalho, por meio da Portaria $n^{\circ}$ 52, de 24.01.2014 "com a finalidade de realizar estudos sobre a criação de instituição de educação superior intercultural indígena que promova, por meio do ensino, pesquisa e extensão, atividades voltadas para a valorização dos patrimônios epistemológicos, culturais e linguísticos dos povos indígenas, considerando-se suas demandas e necessidades”, dentro dos territórios etnoeducacionais.

Na sua visão de futuro, a Universidade Paiterey terá como característica ser aberta, isto é, possibilitará o acesso de outros povos indígenas e dos moradores da região e deverá contar nos primeiros anos com a participação de professores das faculdades e universidades brasileiras que desenvolvem atividades educacionais com indígenas.

Posteriormente, a aspiração é que com a formação de professores indígenas para o exercício da docência superior, esses possam compor o quadro efetivo de profissionais, evidenciando que na atualidade alguns 
Paiter Suruí possuem curso acadêmico nas áreas de direito, administração, turismo, biologia e em fase de conclusão em educação intercultural.

Na estratégia de formação de profissionais compreendem que é imprescindível que o ensino superior deverá ser estendido para outras áreas do conhecimento, visto que necessitam compreender as questões que estão além daquilo que já conhecem e possuem domínio, considerando a complexidade a que se encontram submetidos. Desta forma, verifica-se o anseio pela busca do conhecimento, e também a ampliação dos seus direitos e a conquista plena da cidadania.

Nesse argumento, os Paiter Suruí têm a clareza que o respeito da sociedade envolvente com a TISS/TIPG se dará com a busca pelo diálogo permanente e com a compreensão dos não indígenas sobre a importância do território, visto que os problemas sociais, políticos e econômicos atinge grande parcela da população brasileira e os ambientais têm influência sobre toda a população do planeta Terra. Assim, a proposição da Universidade Paiterey apresenta-se como um diferencial, que deverá ser construído com a participação dos mais distintos atores sociais que compõem a sociedade nacional.

No contexto educacional e econômico os Paiter Suruí têm contribuído para dialogar com dois mundos, o do indígena e o do não indígena. Para sustentabilidade do seu povo, os Paiter Suruí precisam desses tipos de ferramentas de diálogo entre as culturas, porque é quase impossível voltar a praticar sua vida como era antes de contato.

Para o gerenciamento das complexas e múltiplas atividades os Paiter Suruí construíram um sistema de governança com intenção participação de seus membros, cujas decisões educacionais, políticas, sociais, entre outras, são tomadas democraticamente, conforme pode ser observado na Figura 02.

\section{Figura 02 - Sistema de governança Paiter Suruí}

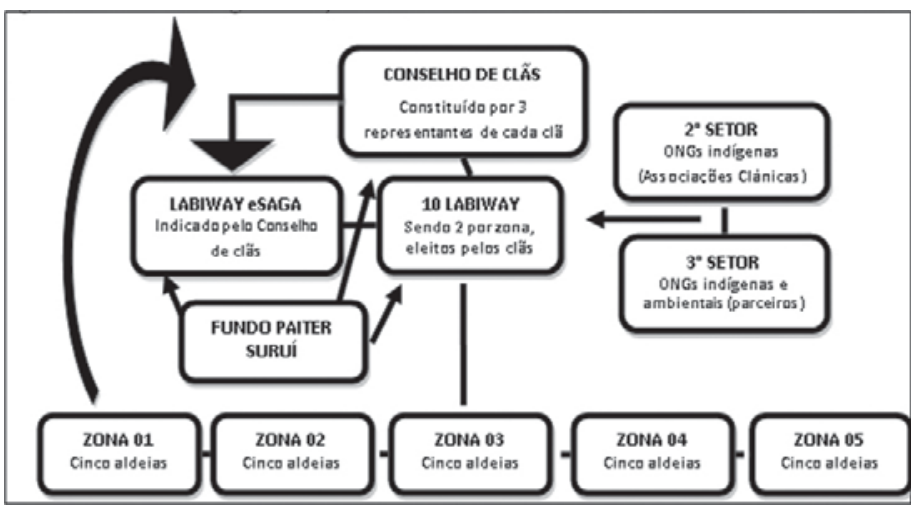

Fonte: Cardozo (2011). 
Na compreensão deste processo de governança - Parlamento Suruí verifica-se que as estratégias políticas são tomadas pelo Conselho de clãs (12), pelas lideranças (10) e pelo Labiway eSaga (líder maior), ouvindo ainda a opinião dos anciões (devido suas experiências), enquanto o $2^{\circ}$ e $3^{\circ}$ setores atuam como assessores, consultores e executores das ações e decisões do Parlamento.

Para administrar os recursos financeiros oriundos de projetos, especialmente do Projeto Carbono Florestal Suruí, foi criado o Fundo Paiter Suruí FPS sendo que está sob a responsabilidade do Fundo Brasileiro para a Biodiversidade - FUNBIO, o qual prestará contas sempre que solicitado pelos Paiter Suruí. Para quaisquer tipos de aplicação dos recursos somente podem ser realizados com o aval do Parlamento Suruí, constituindo-se a educação eleita como prioridade - vários dos discentes que cursam nível superior possuem bolsas de estudos custeadas pelo FPS e assumem o compromisso que ao concluírem os estudos voltem para a TISS/TIPG e repassem o conhecimento adquirido para os demais Paiter Suruí.

A Figura 03 demonstra o nível de interação que os Paiter Suruí mantêm com instituições que atuam direta e indiretamente na TISS/TIPG, sendo que quanto mais ao centro a participação é mais intensa, logo em se trata dos aspectos educacionais formais tem-se a Secretaria de Estado da Educação - SEDUC e Universidade de Brasília - UNB (2ª ordem); Universidade Federal de Rondônia - UNIR, Instituto Federal de Educação, Ciência e Tecnologia de Rondônia - IFRO, Faculdade São Lucas e UNIRON, Museu Goeldi (4ª ordem); Os Serviços de Aprendizagem Industrial, de Aprendizagem Comercial e de Aprendizagem Rural (SENAI, SENAC e SENAR) e Serviço Brasileiro de Apoio às Micro e Pequenas Empresas - SEBRAE, Ministério da Cultura (6 ${ }^{\mathrm{a}}$ ordem), sendo que esses órgãos atuam de forma não sistêmica.

\section{Figura 03 - Nível de interação entre os Paiter Suruí e as instituições que atuam na TISS/TIPG}

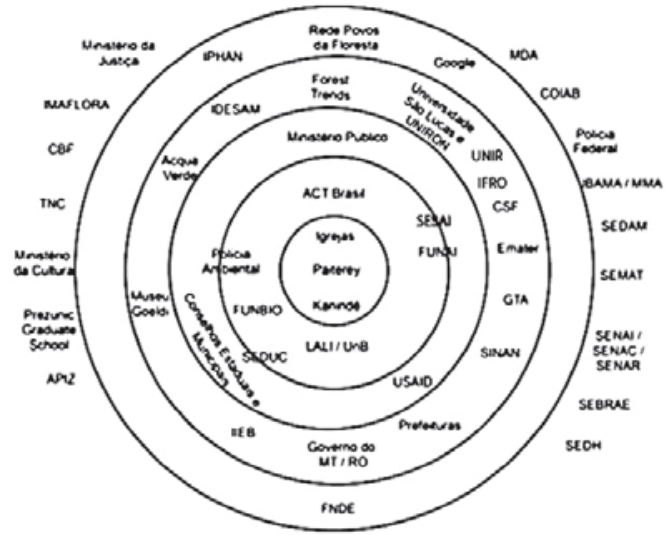

Fonte: ECAM/Metareilá (2011) apud Cardozo (2013). 
Neste sentido, os Paiter Suruí encontram-se receptivos a formar novas parcerias que lhes permitam adquirir e ampliar conhecimento sobre a sociedade envolvente e assim destacam três eixos estratégicos que oportunizará a conquista de uma cidadania efetiva e maior visibilidade social:

1) Educação Básica Intercultural nas línguas Portuguesa e TupiMondé: procura garantir que discentes e docentes tenham a oportunidade de educação e do domínio vernáculo da comunicação nessas duas línguas. Para tanto, entendem que essa conquista virá com a concepção um projeto político-pedagógico diferenciado pensado estrategicamente e que considere o etnoconhecimento e o conhecimento sistematizado/acadêmico-científico, tendo como finalidade a viabilização do ensino e aprendizagem da segunda língua vinculada à sociabilidade e a interculturalidade entre as pessoas que residem na TISS/TIPG e com moradores da região;

2) Divulgação da Cultura Paiter Suruí: refere-se à preservação, difusão da cultura e potencialidades deste povo, ou seja, oportunizará a sociedade envolvente em realizar visitas à TISS/TIPG, o que possibilitará o conhecimento e o diálogo direto com os indígenas. Esse componente está inserido no Plano de Negócio de Ecoturismo, também através da Internet, tendo como objetivo abranger pessoas em nível global e com isso oportunizar a geração de renda e trabalho aos Paiter Suruí. Na concepção deste Plano, os recursos digitais devem ser usados para romper o isolamento tecnológico vivido em muitas comunidades vivem e também para vencer a barreira da falta de espaço que essas têm nas mídias tradicionais. O Mapa Cultural que pode ser inserido frequentemente uma série de informações constitui-se como o primeiro passo em direção ao atingimento do objetivo proposto como propagação da cultura dos Paiterey. Com as estruturas pensadas como o Centro de Formação Paiter Suruí, o Centro de Cultura e Tecnologia, a Escola Agroambiental Paiterey e a Universidade Paiterey as práticas educacionais e culturais serão potencializadas, inclusive no que se refere à educação ambiental que atenderá, prioritariamente, as escolas localizadas na região de influência da TISS/TIPG.

3) Denúncia de Crimes Ambientais: apresenta-se como objetivo de despertar e disseminar a consciência ambiental que, apesar do recente crescimento, ainda não é uma regra entre os cidadãos. Verifica-se rotineiramente que o desrespeito com a natureza em muitos lugares é muito expressivo, a minimização dos problemas ambientais se efetivará no momento em que a população resolva contribuir, através de fiscalização e apoio aos órgãos responsáveis. Neste contexto, as ações de educação ambiental são importantes, pois tem o objetivo de conscientizar a população em geral sobre a relevância da preservação/conservação da natureza e ao uso adequado dos recursos naturais existentes. 
Embora, a educação superior não possua um eixo estratégico específico dentro do Plano de Gestão, entendemos que em longo prazo em decorrência de futuras demandas, esse componente seja incluso para que se atinja aos objetivos indicados pelos Paiter Suruí. Isso porque se trata de um processo em construção, o qual este povo tem apresentado como vanguarda na luta pelos seus direitos e inspirado outras etnias na busca de soluções que visam garantir-lhes a sobrevivência física, cultural, espiritual, social, política, ambiental e territorial.

Neste sentido, utilizamos da preleção de Almir Narayamoga Suruí quando da outorga do título de Doutor Honoris Causa em 2012, a qual possui todo o sentido do papel da educação, da cultura, do aprendizado e do respeito não somente para os indígenas, mas a toda população da Terra:

Alertamos que, assim como os Paiter precisam da floresta para continuar vivendo como povo, toda a humanidade também precisa, e se não houver uma mudança na forma como a floresta vem sendo explorada e destruída, todo o planeta corre o risco de desaparecer. Exigimos respeito à nossa terra, aprendemos com os antigos no dia-a-dia a valorizar a cultura Paiter Suruí e nossa mãe Terra, que nos dá tudo, a medicina, o respeito à história de nossas conquistas e principalmente nos dá a vida.

Aqui se inscreve claramente que um dos meios para se garantir a sobrevivência da humanidade é exatamente que a educação poderá proporcionar mudanças positivas no trato que fazemos com a Terra, com a floresta e com os demais seres existentes e que passa necessariamente pelo respeito e pelo uso adequado do nosso Planeta.

\section{Considerações finais não conclusivas}

A análise das questões educacionais descrevem as problemáticas enfrentadas pelos Paiter Suruí, em decorrência do contato estabelecido há pouco mais de quarenta anos e cujo desdobramento implicou na descaracterização de seu território, influenciando ainda sobre os valores simbólicos, culturais, políticos e de seus saberes.

É preciso destacar que a educação formal aplicada dentro de seu território promoveu uma série de mudanças e continua a influenciar o povo, que entre outros questionários consideram que não é a ideal, portanto, propõe como estratégia uma nova concepção de educação focalizada em suas experiências (o etnoconhecimento) e o conhecimento acadêmico-científico sistematizado, tendo como fundamento a junção entre a língua materna e a portuguesa.

Desse modo, os Paiter Suruí possuem a clareza que é indispensável à permanência de seus valores culturais e conhecimentos e que estes devem ser acrescentados à apreensão de novas concepções educacionais, que possibilitem compreender os códigos, signos, sentidos e significados de 
outras culturas e com isso alcancem a visibilidade como povo.

As articulações políticas internas e externas que os Paiter Suruí realizaram, já apresentam alguns resultados expressivos e promissores devido à ousadia estratégica de seus planos, projetos e programas na firmação de parcerias, permite-nos em nossa análise considerar que os objetivos traçados para uma educação diferenciada, plural e integradora se transforme em realidade dentro de poucos anos, e que podem servir como referencial para outros povos indígenas do Brasil e da América Latina, assim como para a definição de políticas públicas junto aos organismos oficiais e não governamentais.

Assim, afirmamos que a construção da educação escolar indígena é um grande desafio que os Paiter Suruí ambicionam estrategicamente desenvolver e almejam um ensino diferenciado em que consideram a realidade externa devido às relações com a sociedade envolvente, mas sem abdicar da sua cultura, de seus valores, de sua identidade étnica.

Em tal sentido o Centro de Formação Paiter Suruí é uma realidade que tem produzido bons resultados e a proposição do Centro de Cultura e Tecnologia Paiter, da Escola Agroambiental Paiterey e da Universidade Paiterey são estratégias que permitirão a este povo ampliar o diálogo com a sociedade brasileira e internacional, sendo ainda importantes ferramentas ao processo de permanência cultural e de sobrevivência física e territorial, onde a educação é considerada como uma das principais sustentações para a aquisição de novos conhecimentos, a ampliação de seus direitos e a conquista plena da cidadania. 
Polis, Revista Latinoamericana, Volumen 13, $N^{\circ}$ 38, 2014

\section{Notas}

${ }^{1}$ http://www.google.com/intl/pt-br/earth/outreach/stories/surui.html. Acesso em 19 abril 2014.

${ }^{2}$ http://paiter.org/mapa/. Acesso em 10 maio 2014. 


\section{Bibliografía}

Almeida Silva, Adnilson (2010), Territorialidades e Identidade do Coletivo Kawahib da Terra Indígena Uru-Eu-Wau-Wau em Rondônia: “Orevaki Are” (reencontro) dos “marcadores territoriais", Tese de Doutorado em Geografia, UFPR/SCT/DG/PPGMDG, Curitiba. 301 p.

Idem (2012), “A questão indígena em Rondônia e os projetos de desenvolvimento na Amazônia Ocidental”, em Ciência Geográfica, v. XVI, p. 8-14, Bauru. Disponível em http://www.agbbauru.org.br/publicacoes/ revista/anoXVI_1/agb_xvi1_versao_internet/AGB_abr2012_02.pdf. Acesso em 10 dezembro 2013.

Idem (2011), “Representações Indígenas: Territorialidades e Identidade Uma Aproximação Teórica”, em Revista RA’E GA - UFPR, n. 23, p.238262, Curitiba. Disponível em http://ojs.c3sl.ufpr.br/ojs/index.php/raega/ article/view/24839/16647. Acesso em 15 dezembro 2013.

Idem \& Leandro, Ederson Lauri (2010), “Questão Indígena na Amazônia, a especificidade de Rondônia: algumas considerações”, em Amaral, José Januário de Oliveira \& Leandro, Ederson Lauri (orgs), Amazônia e Cenários Indígenas, Pedro e João Editores, São Carlos. pp.45-70.

Badie, Maria Victoria Cebolla (2008), “Espacio, territorio y resistencia simbólica en los Mbya de Misiones, Argentina” en Resistencia y Territorialidad: movimientos indígenas y afroamericanos, em Canal, Gemma Orobitg; Laviña, Javier (Comp.). Serie Estudios de Antropología Social y Cultural 15, Departamento de Antropología Social e Historia de América y Africa, Universidad de Barcelona. pp. 289-311.

Bavaresco, Andréia et al. (Org.) (2011), Pamine: o renascer da floresta. Supernova Design, Brasília.

Cardozo, Ivaneide Bandeira (2013), Iwaí e Metare: a marca do território Paiter Suruí, Dissertação de Mestrado em Geografia. PPGG/UNIR, Porto Velho. 81p.

Idem (Org.) (2011), Etnozoneamento Paiterey Garah: Terra Indígena Sete de Setembro, Kanindé - Associação de Defesa Etnoambiental, Porto Velho.

Idem (org) (2010), Metodologia de diagnóstico etnoambiental participativo e etnozoneamento em terras indígenas. ACT Brasil, Brasília.

Euler, Ana et al.(2008), O Fim da Floresta? A devastação das Unidades de Conservação e Terras Indígenas no Estado de Rondônia, Grupo de Trabalho Amazônico-GTA-Regional Rondônia, Porto Velho.

FUNAI (2005), Legislação Indigenista Brasileira e Normas Correlatas, 3.ed., FUNAI/CGDOC, Brasília. 
Gallois, Dominique (2004), “Terras ocupadas? Territórios? Territorialidades? "em $O$ desafio das sobreposições terras indígenas \& unidades de conservação da natureza, Instituto Sócio Ambiental (ISA), Brasília.

Google (s.d.), Chefe Almir e a tribo Suruí da Amazônia. Disponível em http://www.google.com/intl/pt-br/earth/outreach/stories/surui.html. Acesso em 19 abril 2014.

Kanindé \& Metairelá (2009), Plano de Gestão Etnoambiental da Terra Indígena Sete de Setembro, Kanindé/Metareilá, Porto Velho.

Leandro, Ederson Lauri (2011), Ecoturismo indígena e gestão territorial, contribuições participativas da terra indígena Paiterey Karah (Sete de Setembro), Dissertação de Mestrado em Geografia, PPGG/UNIR, Porto Velho. 134 p.

Léfèbvre, Henri (1980), La Présence et L’Absence, Casterman, Paris.

MEC (2014), Educação Superior: Criação de universidade indígena começa a ser discutida em março. Disponível em http://portal.mec.gov.br/ index.php?option=com_content\&view=article\&id=20183. Acesso em 07 maio 2014.

Mindlin, Betty (1985), Nós Paiter: os Suruí de Rondônia, Editora Vozes, Petrópolis.

Paiter (s.d.), Suruí Mapa Cultural. Disponível em http://paiter.org/mapa/. Acesso em 10 maio 2014.

Rua, João (2005), "Desenvolvimento: em busca da regeneração de um conceito”, em Anais do X Encontro de Geógrafos da América Latina, Universidade de São Paulo, São Paulo. pp. 12999-13024. Disponível em http://observatoriogeograficoamericalatina.org.mx/egal10/Teoriaymetodo/ Teoricos/10.pdf. Acesso em 08 maio 2014.

Santos, Ailton Dias dos (Org.) (2005), Metodologias participativas: caminhos para o fortalecimento de espaços públicos socioambientais, Peirópolis, São Paulo.

Suruí Carbono (s.d). Disponível em http://www.kaninde.org.br/upload/2012/ 04/folder_vers_o_final_1334543440.pdf. Acesso em 05 maio 2014.

Suruí, Chicoepab (2013), Reflorestamento da Terra Indígena Sete de Setembro: uma mudança da percepção e da conduta do povo Paiter Suruí de Rondônia?, Dissertação de Mestrado Profissional em Desenvolvimento Sustentável, CDS/UNB, Brasília. Disponível em http://repositorio.unb.br/ bitstream/10482/14338/1/2013_ChicoepabSuru\%C3\%AD.pdf. Acesso em 30 abril 2014. 
Wilde, Guillermo (2007), “De la depredación a la conservación: génesis y evolución del discurso hegemónico sobre la selva misionera y sus habitantes”, em Ambient. soc.[online], vol.10, n.1. pp. 87-106. Disponível em http://www.scielo.br/pdf/asoc/v10n1/v10n1a06.pdf. Acesso em 06 maio 2014.

Recibido: 13.05.2014

Aceptado: 15.07.2014 